\title{
Altered secretory and neuroprotective function of the choroid plexus in progressive multiple sclerosis
}

\author{
Sabela Rodríguez-Lorenzo ${ }^{1}$, David Miguel Ferreira Francisco ${ }^{2}$, Ricardo Vos ${ }^{3}$, Bert van het Hof ${ }^{1}$, Merel Rijnsburger ${ }^{1}$, \\ Horst Schroten ${ }^{4}$, Hiroshi Ishikawa ${ }^{5}$, Wissam Beaino ${ }^{3}$, Rémy Bruggmann ${ }^{2}$, Gijs Kooij ${ }^{1+}$ and Helga E. de Vries ${ }^{1,6^{*}+}$
}

\begin{abstract}
The choroid plexus (CP) is a key regulator of the central nervous system (CNS) homeostasis through its secretory, immunological and barrier properties. Accumulating evidence suggests that the CP plays a pivotal role in the pathogenesis of multiple sclerosis (MS), but the underlying mechanisms remain largely elusive. To get a comprehensive view on the role of the CP in MS, we studied transcriptomic alterations of the human CP in progressive MS and non-neurological disease controls using RNA sequencing. We identified 17 genes with significantly higher expression in progressive MS patients relative to that in controls. Among them is the newly described long non-coding RNA HIFIA-AS3. Next to that, we uncovered disease-affected pathways related to hypoxia, secretion and neuroprotection, while only subtle immunological and no barrier alterations were observed. In an ex vivo CP explant model, a subset of the upregulated genes responded in a similar way to hypoxic conditions. Our results suggest a deregulation of the Hypoxia-Inducible Factor (HIF)-1 pathway in progressive MS CP. Importantly, cerebrospinal fluid levels of the hypoxia-responsive secreted peptide PAI-1 were higher in MS patients with high disability relative to those with low disability. These findings provide for the first time a complete overview of the CP transcriptome in health and disease, and suggest that the CP environment becomes hypoxic in progressive MS patients, highlighting the altered secretory and neuroprotective properties of the CP under neuropathological conditions. Together, these findings provide novel insights to target the CP and promote the secretion of neuroprotective factors into the CNS of progressive MS patients.
\end{abstract}

Keywords: Choroid plexus, Multiple sclerosis (MS), RNA-sequencing, Cerebrospinal fluid (CSF), Hypoxia, PAl-1

\section{Introduction}

Multiple sclerosis (MS) is a chronic demyelinating disorder of the central nervous system (CNS) affecting 2.3 million people worldwide [59]. Most MS patients initially present a

\footnotetext{
* Correspondence: he.devries@amsterdamumc.nl

${ }^{\dagger}$ Gijs Kooij and Helga E. de Vries contributed equally to this work.

'Department of Molecular Cell Biology and Immunology, Amsterdam Neuroscience, MS Center Amsterdam, Amsterdam UMC, Vrije Universiteit Amsterdam, de Boelelaan 1117, 1007 MB Amsterdam, Netherlands ${ }^{6}$ Medical Biochemistry, Amsterdam Cardiovascular Sciences, Amsterdam UMC, University of Amsterdam, Meibergdreef 9, Amsterdam 1105 AZ, the Netherlands

Full list of author information is available at the end of the article
}

relapsing-remitting phase, in which peaks of the disease coincide with the appearance or reactivation of inflammatory lesions in the brain and spinal cord [46], followed by periods of inactivity. Eventually, irreversible neurological damage accumulates, and secondary progressive MS develops. A small subset of patients follows a progressive course from the onset of the disease, known as primary progressive MS. Neurodegeneration, brain atrophy and a steady increase of clinical disability are features of both primary and secondary progressive MS, together affecting $43 \%$ of MS patients [7]. While several treatments are available for the inflammation-driven relapsing-remitting phase of MS, immune-modulators are

(c) The Author(s). 2020 Open Access This article is licensed under a Creative Commons Attribution 4.0 International License, which permits use, sharing, adaptation, distribution and reproduction in any medium or format, as long as you give appropriate credit to the original author(s) and the source, provide a link to the Creative Commons licence, and indicate if changes were made. The images or other third party material in this article are included in the article's Creative Commons licence, unless indicated otherwise in a credit line to the material. If material is not included in the article's Creative Commons licence and your intended use is not permitted by statutory regulation or exceeds the permitted use, you will need to obtain permission directly from the copyright holder. To view a copy of this licence, visit http://creativecommons.org/licenses/by/4.0/ The Creative Commons Public Domain Dedication waiver (http://creativecommons.org/publicdomain/zero/1.0/) applies to the data made available in this article, unless otherwise stated in a credit line to the data. 
less effective in progressive MS, indicating a need for new restorative therapies for this disease phase. Inflammation is present in all stages of MS, but in progressive MS it may be trapped behind the restored blood brain barrier, making it thus inaccessible to immunomodulatory treatments [39]. Moreover, oxidative stress and iron accumulation can magnify neurological damage in progressive MS [39]. Thus, the development of novel therapies that halt the neurodegenerative process and/or promote neuroprotection may be vital to combat progressive MS.

The choroid plexus (CP) is a strategically located villous structure that actively regulates CNS homeostasis [5]. There are four CP located in each of the brain ventricles, consisting of highly vascularized stroma surrounded by a tight layer of epithelial cells that form the blood-cerebrospinal fluid barrier (BCSFB) [22]. The CP is the main producer of cerebrospinal fluid (CSF), and secretes a remarkable amount of signaling and trophic factors into the CNS. Moreover, the CP is capable of sensing and integrating stimuli from the periphery and CNS and coordinate secretory responses [22].

In the past years, there is increasing evidence of the involvement of the $\mathrm{CP}$ in a variety of disorders such as ageing $[3,16,83]$, Alzheimer's disease [30, 70], frontotemporal dementia [70], schizophrenia [34], Huntington's disease [70] and cerebral ischemia [66]. In MS, the presence of periventricular lesions and the increased numbers of immune cells in the CSF [11] suggest an involvement of the CP in regulating pathology. In the mouse model for MS, called experimental autoimmune encephalomyelitis (EAE), the first wave of immune cell infiltration is thought to occur through the $\mathrm{CP}$, by means of the interaction of Th17 cells with the CP epithelium-derived chemokine CCL20 [58]. In humans, activation of immune cell populations and adhesion mechanisms have been described in the CP from MS patients $[65,77]$. Alterations in the BCSFB that could result in immune cell infiltration into the CNS have also been studied both in EAE and MS, with variable results [13, 37]. However, changes in the secretory activity of the CP in MS have not been explored. Given its critical contribution to CNS homeostasis through the production of CSF, the CP is a strong candidate to influence MS pathogenesis.

To get a comprehensive overview of $\mathrm{CP}$ alterations in progressive MS and reveal potential disruptions in any of its critical attributes, including secretion, barrier formation or the immunological milieu, we performed RNA sequencing (RNA-seq) of human postmortem CP samples from the lateral ventricle of progressive MS patients and nonneurological controls. We here provide an overview on the CP transcriptomic alterations in progressive MS, including hypoxia-responsive, neuroprotective and secretory changes. Our findings suggest a deregulation of the HypoxiaInducible Factor (HIF)-1 pathway in progressive MS CP. These transcriptional changes are accompanied by altered levels of the hypoxia-responsive secreted peptide plasminogen activator inhibitor-1 (PAI-1) in the CSF of MS patients. Our data suggest that the $\mathrm{CP}$ epithelium is a source of secreted peptides into the CSF during progressive MS that can regulate CNS homeostatic responses. Together, this study provides the first characterization of the transcriptomic profile of the CP in progressive MS, pointing to hypoxia-related and neuroprotective responses and to a dysregulation in peptide secretion which may have important effects on CNS homeostasis during MS pathogenesis.

\section{Materials and methods Human samples}

Tissue was obtained from patients with clinically diagnosed and neuro-pathologically confirmed progressive MS as well as from control cases without neurological disease by rapid autopsy and immediately frozen in liquid nitrogen. $\mathrm{CP}$ tissue from the lateral ventricles was obtained from the Netherlands Brain Bank, while brain tissue was obtained from the UK MS Society Tissue Bank, Imperial College London. All parties received permission to perform autopsies, for the use of tissue and for access to medical records for research purposes. All donors, or their next of kin, had given informed consent for autopsy and use of their brain tissue for research purposes. Relevant clinical information of CP donors for RNA-seq is summarized in Supplementary Table 1. For CP culturing experiments, donor information is summarized in Supplementary Table 2. Clinical data of brain donors are listed in Supplementary Table 4. Lesions were immunohistochemically characterized as areas with abundant immune cell infiltrates (MHCII+ cells) and extensive myelin loss (proteolipid protein, PLP).

CSF samples were obtained from the Karolinska Institute biobank containing samples collected during routine neurological diagnostic work-up. A total of 58 subjects were included in this study. MS patients fulfilling the McDonald criteria included RRMS, SPMS and PPMS. The control cohort included non-inflammatory or inflammatory neurological disease controls, symptomatic controls, and healthy controls. Classification and scoring of MS patients was assessed by trained neurologists. For RRMS, a relapse was defined as an increase with $\geq 1$ point on the EDSS with a duration of at least 1 week before sampling, while remission was defined as a stable status longer than 3 months prior to sampling. SPMS was defined as an initial relapsing-remitting disease course followed by more than 12 months of continuous worsening of neurological function, with or without occasional relapses. At time of sampling, none of the patients were treated with immunomodulatory drugs. CSF donors received verbal and written information and gave consent in writing before inclusion in the study. CSF samples were centrifuged immediately after sampling to isolate the cells and larger particles and stored frozen at $-80^{\circ} \mathrm{C}$ until analysis. CSF sample information is summarized in Supplementary Table 3. 


\section{RNA sequencing and analysis}

Up to $30 \mathrm{mg}$ of tissue was collected from the whole lateral CP by cutting slices approximately $10 \mu \mathrm{m}$ thick using a cyrotome at $-20^{\circ} \mathrm{C}$. Tissue was homogenized with a POLYTRON PT 1200 (Kinematica). Total RNA from the CP was extracted with the RNeasy mini kit (Qiagen, 74104), following the manufacturer's instructions. After extraction, the quality of the RNA was assessed using a Fragment Analyzer. Samples with RIN values $\geq 6.5$ were selected (Supplementary Table 1). Of these, 6 were from non-neurological controls (4 females, 2 males; average age of $62 \pm 6.11$ ) and the remaining 6 from individuals with diagnosed progressive MS ( 2 females, 4 males; average age of $61 \pm 11.15$ ) (Supplementary Table 1). The RNA libraries for the selected 12 samples were prepared according to the manufacturer's instructions using TruSeq stranded mRNA Library Prep Kit including an rRNA depletion step (RiboMinus, ThermoFisher). Sequencing was performed at the Next Generation Sequencing (NGS) Platform of the University of Bern using a HiSeq3000 producing paired-end reads with an average depth of approximately 30 million reads per sample (ranging approximately from 28 to 32 million reads) with a read length of $2 \times 150$ bases.

RNA-seq analysis was performed as follows: the quality of the fastq files was assessed using FASTQC software [4] (version 0.11.5). The reads were aligned to the human reference genome (version GRCh38) using TopHat2 [33] (version 2.1.1). Qualimap [21] (version 2.2.1) was used for quality control and IGV [63] (version 2.3.69) for visualization of the aligned reads. Read counts by transcript were determined by using HTSeq-count [32] (version 0.6.1). Normalization and differential expression analysis were performed with the DESeq2 package [45] (Version 1.16.1) in R [74] (Version 3.4.0). The SVA (Version 3.24.4) package [41] was used to test for batch effects among the samples. Genes with an adjusted $p$-value (False Discovery Rate) $\leq 0.05$ were selected for further analysis.

Differential alternative splicing analysis was performed based on the same fastq files as for the gene level based RNA-Seq analysis. The reads were aligned to the human reference genome (version GRCh38) using Hisat2 [32] (Version 2.1.0) and subsequently sorted by coordinates using Samtools [42] (version 1.3). Stringtie [57] (version 1.3.3b) was then used to predict, merge and estimate the abundance of the different transcripts. Finally, differential expression assessment, visualization and annotation of the transcripts was done in $\mathrm{R}$ [74] (Version 3.4.3) using the Ballgown package [19] (Version 2.10.0) with parallel use of the Limma [61] (Version 3.34.0) and edgeR [64] packages (version 3.20.1) for analysis with regularization.

\section{Validation of differentially expressed genes by qPCR}

To validate differentially expressed genes from the RNAseq experiment, the same RNA of CP samples was analyzed by quantitative PCR (qPCR). RNA was reverse- transcribed into cDNA with the High-Capacity cDNA Reverse Transcription Kit (4368814, Thermo Fisher Scientific). qPCR reactions were performed in technical duplicates on an Applied Biosystems Viia7 real-time PCR machine (Thermo Fisher Scientific) using SYBR green detection. Primers were obtained from Thermo Fisher Scientific, and their sequences are given in Supplementary Table 5. Normfinder was used to select GAPDH and $18 \mathrm{~s}$ $r R N A$ as the most stable reference genes in MS and control $\mathrm{CP}$ among a set of 8 candidates.

\section{Choroid plexus explants culture}

Fresh human postmortem $\mathrm{CP}$ was stored in Hibernate A medium (A1247501, Thermo Fisher Scientific) for less than $24 \mathrm{~h}$. The CP was washed twice in cold PBS and cut with sharp scissors into small pieces (around $3 \mathrm{~mm}^{2}$ each). Pieces from one donor were split into two different plates with DMEM/F12 (31330-038, Gibco) supplemented with $10 \%(\mathrm{v} / \mathrm{v})$ heat inactivated FCS, and $1 \%$ PSG). Both plates with explants were cultured under normoxic conditions $\left(20 \% \mathrm{O}_{2}\right)$ for $24 \mathrm{~h}$, after which one plate was switched to hypoxia $\left(1 \% \mathrm{O}_{2}\right)$ for another $24 \mathrm{~h}$. Then, CP explants were washed twice with cold PBS and RNA extraction was performed with TrizOL (15596026, Invitrogen) using a blend homogenizer and a $21 \mathrm{G}$ syringe for tissue disruption.

\section{Immunoassays of ADM, PAl-1 and STC2 in CSF}

Determination of ADM protein concentration in human CSF was performed with a competitive radioimmunoassay method (RK-010-01, Phoenix Pharmaceuticals), following the manufacturer's instructions. CSF samples were concentrated $5 \mathrm{X}$ by lyophilization and resolubilization in sterile water to adjust to the detection range of the assay $(100-12,800 \mathrm{pg} / \mathrm{mL})$. PAI-1 concentration in human CSF was measured using a sandwich ELISA (ab108891, Abcam) following the manufacturer's instructions. STC2 concentration in human CSF samples was measured using a sandwich ELISA (AL-143, AnshLabs) following the manufacturer's instructions. Investigators were blinded to sample type during experiments and data collection.

\section{RNA isolation from brain MS lesions and control tissue}

Active and chronic active MS lesions and white matter from controls were dissected from frozen brain blocks. To this aim, lesions were first outlined according to their myelin (PLP) and inflammatory (MHCII) status, using a sharp needle. Thereafter, $10 \mu \mathrm{m}$ sections were cut, and lesion area and normal appearing white matter were collected separately in tubes and kept in liquid nitrogen. Messenger RNA isolation was conducted using the Qiagen RNeasy Lipid Tissue Mini Kit (Qiagen, the Netherlands) according to manufacturer's instructions. 


\section{Choroid plexus epithelial cell culture}

HIBCPP cells (from human choroid plexus papilloma cell line [29]) were cultured in DMEM/F12 (31330-038, Gibco) supplemented with $4.8 \mathrm{mM}$ L-Glutamine (25030024, Gibco), $5 \mu \mathrm{g} / \mathrm{mL}$ insulin (19278, Sigma), penicillin $(100 \mathrm{U} / \mathrm{ml})$ and streptomycin $(100 \mu \mathrm{g} / \mathrm{ml}), 15 \%(\mathrm{v} / \mathrm{v})$ heat inactivated fetal calf serum (FCS). For hypoxia experiments, cells were cultured under normoxic $\left(20 \% \mathrm{O}_{2}\right)$ or hypoxic $\left(1 \% \mathrm{O}_{2}\right)$ conditions for $24 \mathrm{~h}$. For inflammation experiments, cells were treated with $10 \mathrm{ng} / \mathrm{mL}$ recombinant human TNF-a (300-01A) for 24h. Then, cells were washed twice with cold PBS and RNA extraction was performed with TrizOL (15596026, Invitrogen).

Gene expression analysis of HIBCPP cells, CP explants and brain tissue: RT-qPCR

cDNA synthesis was performed using a High-Capacity cDNA Reverse Transcription Kit (4368814, Thermo Fisher Scientific). qPCR reactions were performed in technical duplicate on a Viia7 real-time PCR machine (Thermo Fisher Scientific) using SYBR green detection. Primers were obtained from Thermo Fisher Scientific, and their sequences are given in Supplementary Table 5. Messenger RNA expression levels were normalized using 18 s rRNA or GAPDH.

\section{Statistical analysis}

Statistical analysis was done using $\mathrm{R}$ statistical software version 3.4.0 (2017-04-21). Differences in qPCR gene expression results were tested by two-tailed Welch t-test, except for CP explant data, where differences were tested by paired two-tailed Welch t-test. Immunoassay protein concentration results are expressed as median and interquartile ranges (IQR). The Shapiro-Wilk's test was used to assess the normality of distribution of investigated parameters. The $\mathrm{F}$ test was used to assess heteroscedasticity. Outliers were investigated by Grubbs', Dixon and Chi-squared tests. Differences in normally distributed data were tested by two-tailed Welch t-test, while a two-tailed Wilcoxon rank sum test (MannWhitney U test) with continuity correction was used for non-normally distributed data. Pearson's correlation was used to analyze the association between studied parameters. For dichotomization of the cohort by EDSS score, a cut-off of 5.5 was chosen, based on the EDSS median in the cohort and the clinical significance of the score [51].

\section{Results}

Transcriptional alterations in the CP of progressive MS patients

To reveal potential transcriptomic changes associated with progressive MS, we performed RNA-seq of 6 human CP samples from progressive MS patients and 6 nonneurological disease control CP samples. Differential expression analysis revealed a total of 17 genes with higher expression in the $\mathrm{CP}$ of progressive MS patients compared with that of non-neurological controls (Table 1, Fig. 1a and $b$ ), whereas we did not observe genes with lower expression. Several of the identified genes are involved in hypoxia, such as ADM, HK2, STC2, SERPINE1, SNHG15 and possibly $H I F 1 A-A S 3$, but also in neuroprotection, such as ADM, SERPINE1, MT1A and STC2. These

Table 1 List of differentially expressed genes between MS and control CP

\begin{tabular}{|c|c|c|c|c|c|}
\hline Description & Gene symbol & Ensembl ID & Mean Normalized Reads & log2FoldChange & Adjusted $p$-value \\
\hline RNA U6 small nuclear 2 & RNU6-2 & ENSG00000207357 & 19.74 & 3.46 & $5.86 \mathrm{E}-06$ \\
\hline stanniocalcin 2 & STC2 & ENSG00000113739 & 81.46 & 1.57 & 0.003 \\
\hline lymphatic vessel endothelial hyaluronan receptor 1 & LYVE1 & ENSG00000133800 & 3253.05 & 1.45 & 0.006 \\
\hline MYC proto-oncogene, bHLH transcription factor & MYC & ENSG00000136997 & 236.37 & 1.84 & 0.006 \\
\hline lactate dehydrogenase A pseudogene 4 & LDHAP4 & ENSG00000214110 & 122.50 & 1.31 & 0.011 \\
\hline adrenomedullin & ADM & ENSG00000148926 & 1046.05 & 2.24 & 0.014 \\
\hline eukaryotic translation initiation factor 4A1 & EIF4A1 & ENSG00000161960 & 48.80 & 0.82 & 0.014 \\
\hline small nucleolar RNA host gene 15 & SNHG15 & ENSG00000232956 & 94.54 & 0.92 & 0.016 \\
\hline HIF1A antisense RNA 3 & HIF1A-AS3 & ENSG00000258667 & 63.96 & 1.27 & 0.019 \\
\hline Rho family GTPase 3 & RND3 & ENSG00000115963 & 451.98 & 2.33 & 0.019 \\
\hline serpin family E member 1 & SERPINE1 & ENSG00000106366 & 930.69 & 3.04 & 0.023 \\
\hline teashirt zinc finger homeobox 3 & TSHZ3 & ENSG00000121297 & 109.95 & 0.69 & 0.027 \\
\hline immediate early response 2 & IER2 & ENSG00000160888 & 231.88 & 0.70 & 0.029 \\
\hline metallothionein $1 \mathrm{~A}$ & MT1A & ENSG00000205362 & 71.35 & 4.17 & 0.035 \\
\hline metallothionein $1 \mathrm{X}$ & MT1X & ENSG00000187193 & 34.07 & 3.11 & 0.039 \\
\hline $\mathrm{C}-\mathrm{X}-\mathrm{C}$ motif chemokine ligand 2 & $\mathrm{CXCL2}$ & ENSG00000081041 & 127.95 & 3.63 & 0.047 \\
\hline hexokinase 2 & HK2 & ENSG00000159399 & 572.79 & 1.52 & 0.050 \\
\hline
\end{tabular}




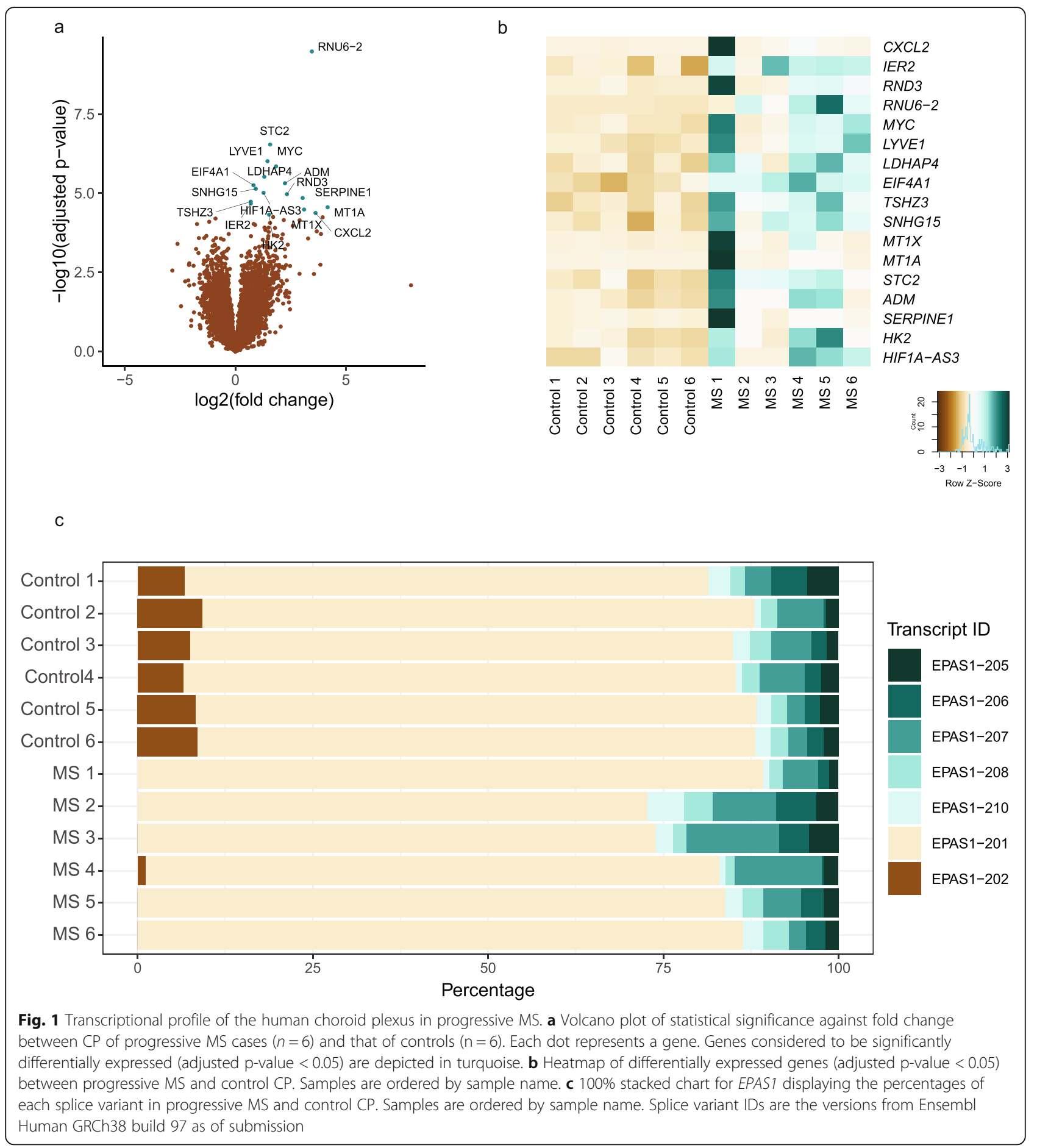

transcriptional alterations were validated in the same human CP samples by qPCR (Supplementary 1a). Accordingly, Gene Ontology (GO) term enrichment analysis in the dataset showed overrepresentation of genes related to hypoxia ('response to hypoxia', GO:0001666, $p=0.001$; 'cellular response to hypoxia' GO:0071456, $p=0.007$ ) (Supplementary Table 6). Surprisingly, only one of the differentially expressed genes, CXCL2, appeared to be directly linked to inflammation, although there was an enrichment in several GO terms related to inflammatory processes (Supplementary Table 6).

In addition to the RNA-seq differential gene expression analysis, we performed differential alternative splicing analysis. Among the whole genome, the expression of one of the transcripts of the gene EPAS1 (EPAS1202), involved in hypoxic responses [80], was either 
completely or nearly lost in the progressive MS samples (Fig. 1c and Supplementary 1b). Together, these results indicate that transcriptomic alterations are apparent in the $\mathrm{CP}$ of progressive MS patients, involving hypoxiaand neuroprotection-related genes.

\section{Hypoxia responses in human $\mathrm{CP}$ explants}

Our RNA-seq analysis revealed the induction of hypoxia responsive genes in the $\mathrm{CP}$ of progressive MS patients, suggesting a hypoxic $\mathrm{CP}$ environment during the disease. To validate these findings, we studied the effect of $\mathrm{CP}$ hypoxia on the differentially expressed hypoxia responsive genes, as assessed by RNA-seq. For this, we cultured human postmortem CP explants in hypoxic $\left(1 \% \mathrm{O}_{2}\right)$ and normoxic $\left(20 \% \mathrm{O}_{2}\right)$ conditions for $24 \mathrm{~h}$ (Fig. 2a). We detected a higher expression of known hypoxia-related genes (HK2, ADM, STC2, SERPINE1 and SNHG15), but also of other genes, to our knowledge, previously unrelated to hypoxia (HIF1AAS3; MT1X, TSHZ3, LDHAP4) (Fig. 2b and Supplementary Table 7). Thus, the transcriptional response to hypoxia in our CP explant model is compatible with the presence of a hypoxic environment in the $\mathrm{CP}$ of progressive MS patients.

\section{Higher PAI-1 (SERPINE1) concentration in the CSF of MS patients with high disability}

The CP has an important secretory function which is key in the maintenance of CNS homeostasis. Our RNA-seq analysis revealed three disease-affected genes encoding for the secreted proteins adrenomedullin (ADM), plasminogen activator inhibitor-1 (PAI-1) and stanniocalcin-2 (STC2) (Fig. 1b). To investigate the alterations of the $\mathrm{CP}$ secretory function in
MS we determined the concentration of ADM, PAI-1 and STC2 in the CSF of MS patients and controls. There was a trend of higher ADM levels in the CSF from MS patients compared to those in controls $(24.61 \mathrm{pg} / \mathrm{mL} \pm 7.05$ vs 22.16 $\mathrm{pg} / \mathrm{mL} \pm 8.09 ; \mathrm{W}=470.5, p=0.034$ ) (Fig. 3a). However, a weak but significant positive correlation between ADM and age was observed $(\mathrm{r}=0.3, p=0.025)$ (Supplementary 3a), while MS cases were significantly older than the controls (Supplementary 3b). There was no correlation with EDSS (Supplementary 3c-d). PAI-1 concentration in the CSF of controls was $0.63 \mathrm{ng} / \mathrm{mL}( \pm 0.18 \mathrm{IQR})$ while in the CSF of MS patients the concentration was $0.75 \mathrm{ng} / \mathrm{mL}( \pm 0.13 \mathrm{IQR})$, but this difference was not significant $(\mathrm{t}=1.82, p=0.079)$ (Fig. 3b). However, PAI-1 levels in the CSF were positively correlated with age $(\mathrm{r}=0.66, p=5.05 \mathrm{e}-05)$ (Supplementary $3 e)$. Interestingly, we did observe significantly higher levels of PAI-1 in the CSF of MS patients with more clinical disability, reflected by the EDSS score $(0.81 \mathrm{ng} / \mathrm{mL} \pm 0.15$ IQR, EDSS score $>5.25$ ) compared with MS patients with a lower disability score $(0.66 \mathrm{ng} / \mathrm{mL} \pm 0.08 \mathrm{IQR}$, EDSS score $<5.25)(\mathrm{t}=$ 2.89, $p=0.009$ ) (Fig. 3c) while the age between these two groups was similar (Supplementary 3f). Lastly, STC2 levels in the CSF from MS patients $(2.77 \mathrm{ng} / \mathrm{mL} \pm 0.54 \mathrm{IQR})$ did not differ from those in controls $(2.69 \mathrm{ng} / \mathrm{mL} \pm 0.27 \mathrm{IQR}$; $\mathrm{t}=-1.317, p=0.198$ ) (Fig. 3d) or between disability states (Supplementary $3 \mathrm{~h}-\mathrm{i}$ ), but STC2 concentration in the CSF was positively correlated with age $(r=0.409$, $p=0.012$ ) (Supplementary 3g).

We next hypothesized that the elevated levels of PAI-1 in the CSF of MS patients originate from the CP. However, as this protein may also be expressed in the brain

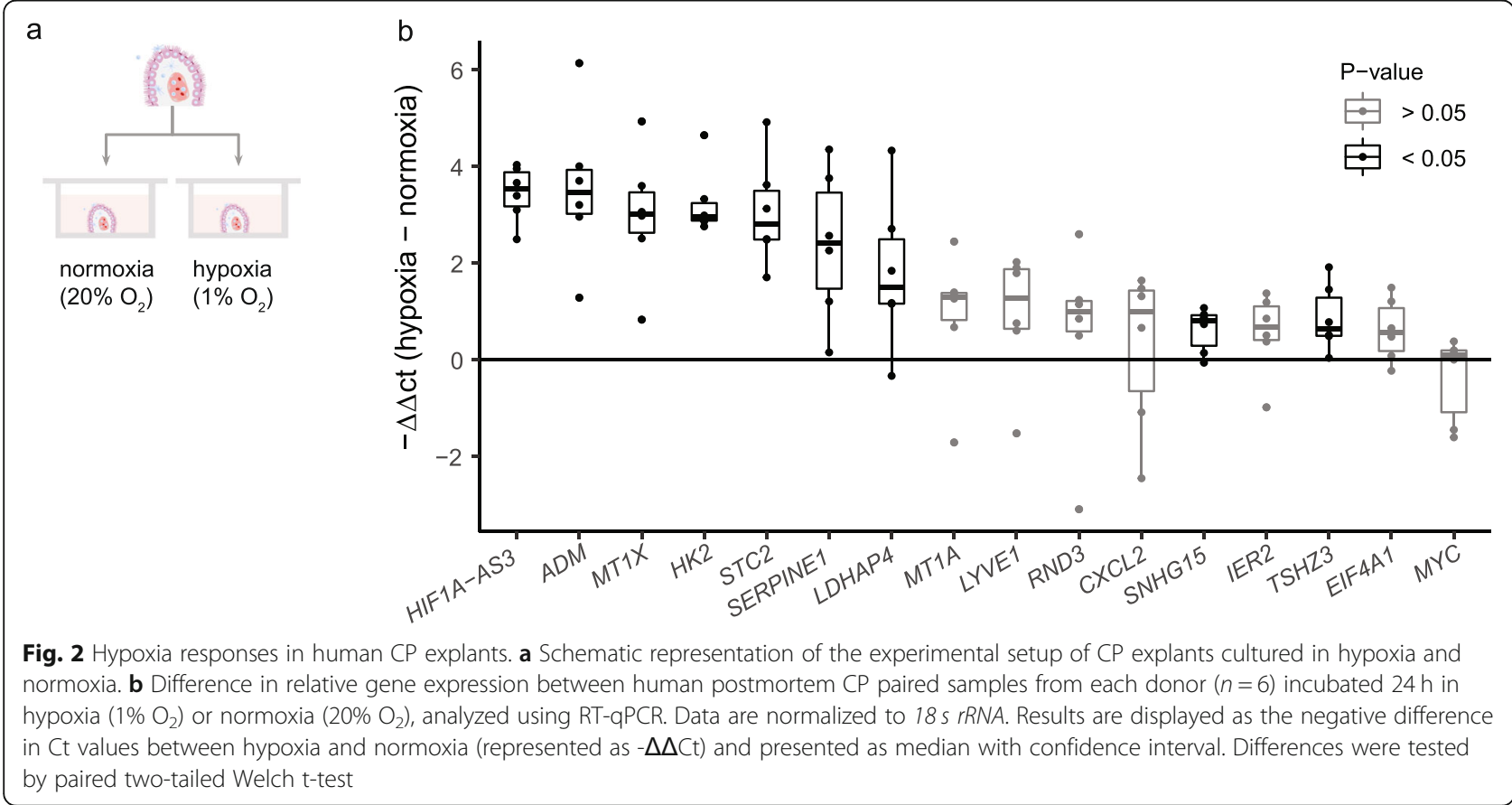




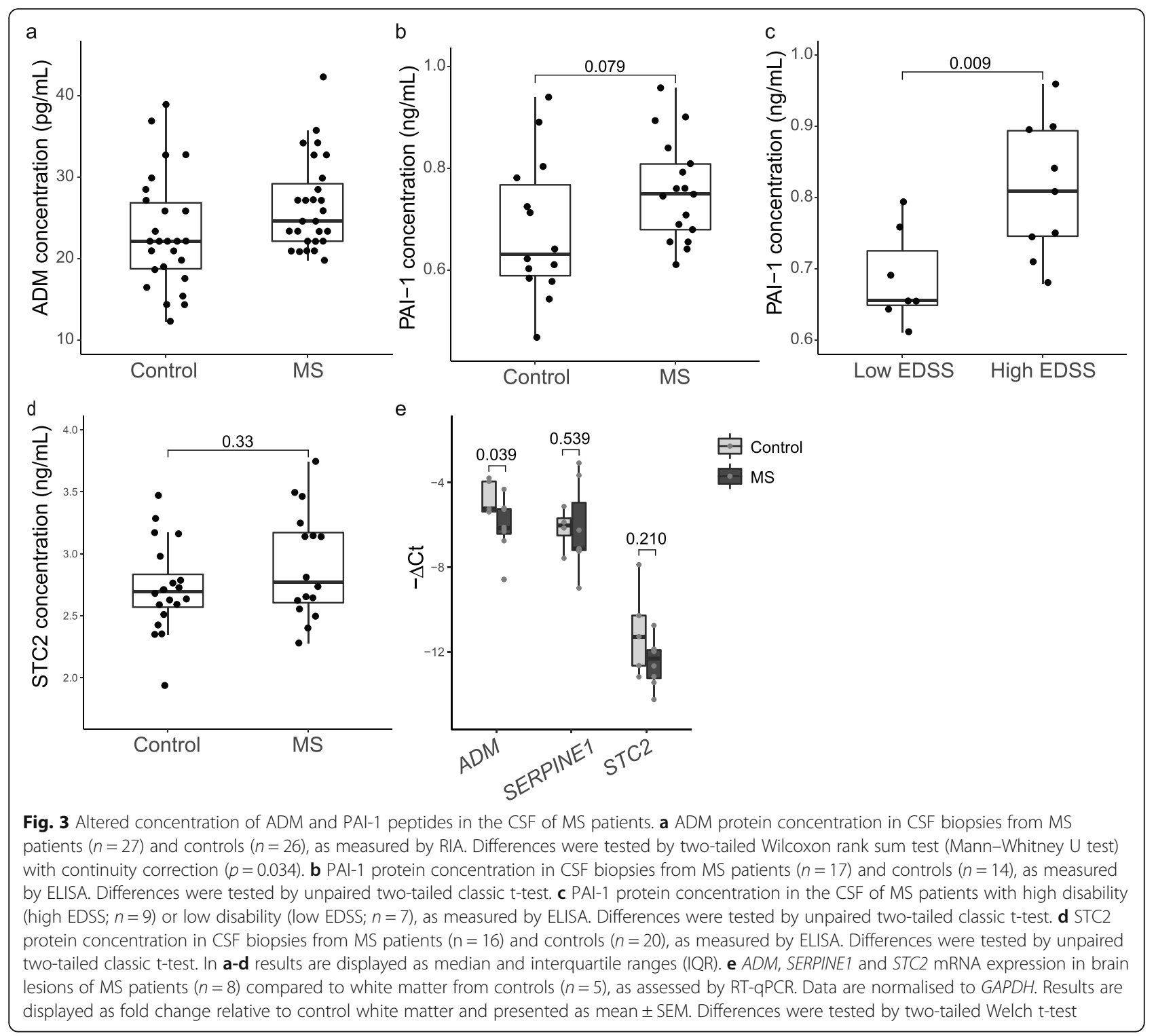

parenchyma [82], we studied gene expression in white matter lesions from progressive MS patients and healthy control brain tissue. Our results show no differences in SERPINE1 (PAI-1) or STC2 expression between the two groups, and even lower expression levels of $A D M(\mathrm{t}=$ $-2.338, p=0.039$ ) are present in MS lesions relative to control (Fig. 3e). In addition to our data from MS lesions, we analyzed an available microarray gene expression dataset of MS brain lesions and control white matter (GEO accession ID: GSE38010) [2, 27]. Similarly to our results, we found lower $A D M$ expression levels in MS lesions compared to control white matter (adjusted $p=0.067$, $\log 2 \mathrm{FC}=-2.19)$, while SERPINE1 and STC2 expression did not differ (Supplementary Fig. 4). These findings suggest that the transcriptomic alterations in the CP of progressive MS patients result in the increased secretion of proteins such as PAI-1 into the CSF.

\section{Expression of ADM, SERPINE1 (PAI-1) and STC2 in choroid plexus epithelial cells}

CP epithelial cells are the main producer of CSF, and ADM and PAI-1 are known to be secreted by CP epithelium $[71,72,76,79]$. In order to confirm the epithelial origin of the enhanced expression of $A D M, P A I-1$ and STC2 in progressive MS (Fig. 4a), we set out to study their gene expression in human $\mathrm{CP}$ epithelial cells (HIBCPP cells). Expression levels of $A D M$ were higher under hypoxic compared to normoxic culture conditions $(\mathrm{t}=2.725, p=0.011$, Fig. $4 \mathrm{~b})$, while we did not see differences in the expression of SERPINE1 or STC2 (Fig. 4b). 


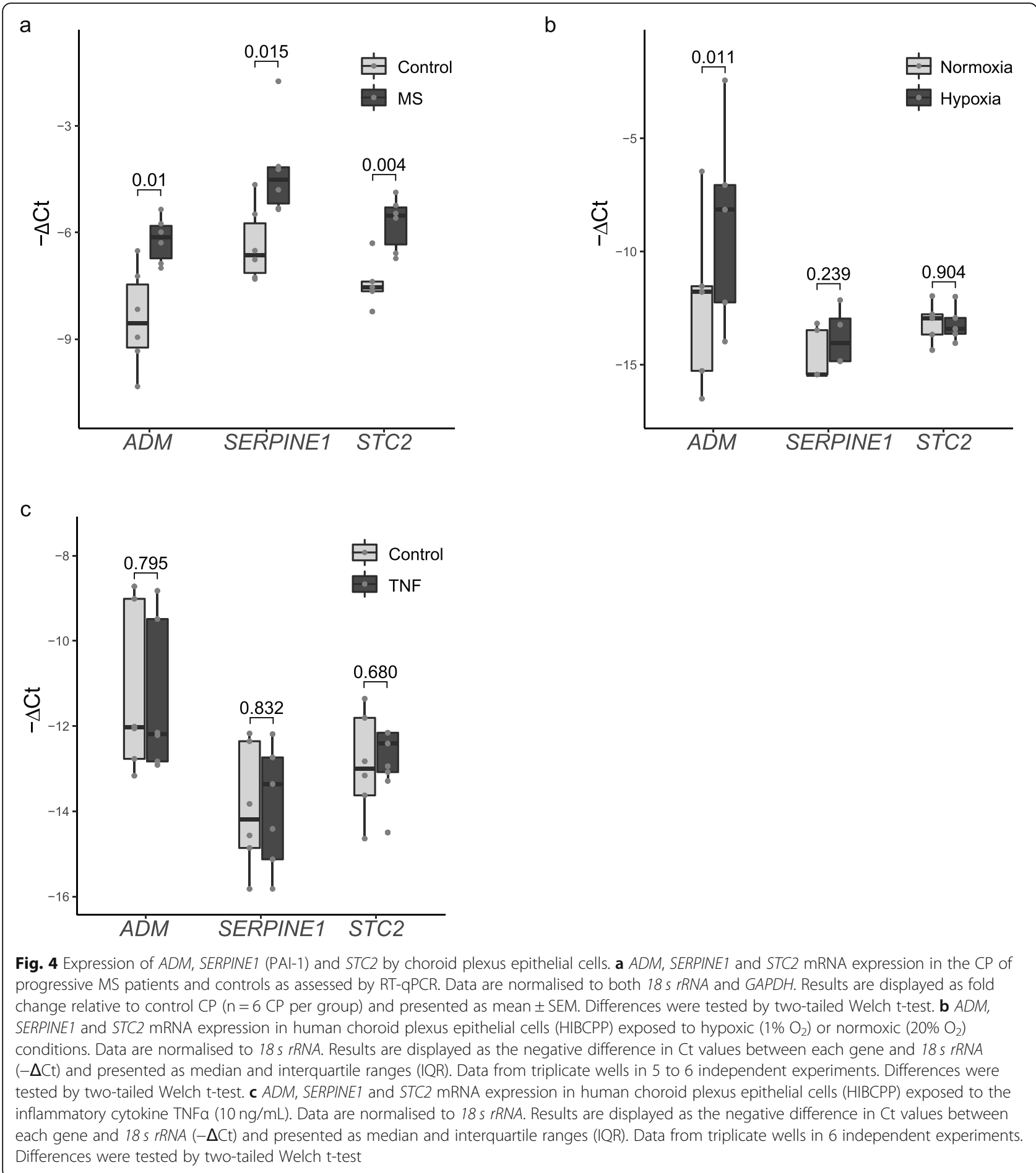

In contrast, $\mathrm{CP}$ epithelial cells exposed to an inflammatory stimulus $(10 \mathrm{ng} / \mathrm{mL}$ TNF-a) did not show altered expression of ADM, SERPINE1 or STC2 relative to control (Fig. 4c). These results indicate that the CP epithelial cells express ADM, SERPINE1 and STC2 and that ADM levels are increased upon hypoxic conditions. Together with the CP explant data (Fig. 2), our results are consistent with the presence of hypoxia in the $\mathrm{CP}$ of progressive MS patients.

\section{Discussion}

In this study, we explored the transcriptional profile of the $\mathrm{CP}$ in progressive MS patients compared to nonneurological controls and how this relates to altered peptide 
concentrations in the CSF of MS patients. We found an enrichment in hypoxia-related, neuroprotective and secretory genes among those differentially expressed, uncovering new important roles of the CP in the pathogenesis of MS. Since the $\mathrm{CP}$ is the main producer of CSF, the relevance of its secretory function was further validated by studying the levels of three of the identified proteins, ADM, PAI-1 (SERPINE1) and STC2, in the CSF of MS patients. We observed a higher concentration of PAI-1 in patients with more disease severity. Finally, we provide supporting evidence for the CP epithelium as the source of these peptides.

To our knowledge, this is the first transcriptomic characterization of the progressive MS CP in a human setting. RNA-seq of the CP in other neurological diseases such as frontotemporal dementia, Alzheimer's and Huntington's disease [70], or schizophrenia [34] revealed alterations in the barrier or immune homeostatic properties of the CP. In progressive MS, we found predominantly alterations related to hypoxia but also secretion and neuroprotection, possibly reflecting the particular etiology of MS.

The postmortem tissue used in this study was carefully selected for high RNA integrity, thereby limiting the availability of samples. Although donors with other neurological diseases were excluded from the study, the high variability of human samples is reflected in our dataset (Supplementary 1d). Additionally, the CP consists of a variety of cells, including epithelial, endothelial and immune cells, fibroblasts and pericytes. Because we performed RNA-seq on the whole tissue, we cannot exclude that subtle yet significant differences in gene expression in specific subsets of cells were undetected.

We report that a considerable number of the genes with higher expression in the $\mathrm{CP}$ of progressive MS patients relative to control $\mathrm{CP}$ are involved in hypoxia, highlighting a novel aspect of the disease pathology in the CP. Genes such as ADM [10, 55], SERPINE1 [35, 67], HK2 [60], STC2 [40] and SNHG15 [73] are upregulated upon hypoxia. The expression of these genes is regulated by the transcription factors HIF-1a and EPAS1 (also known as HIF-2a) [18, 20, 35, 40, 44, 60, 67]. The regulatory function of HIF-1a and EPAS1 occurs at the protein level, as their mRNA levels are not increased in hypoxia [52, 80] (Supplementary 1c and 2a). In addition, we show the involvement in neurological disease of the previously undescribed long non coding RNA HIF1AAS3 (ENSG00000258667). HIF1A-AS3 is one of the three antisense genes of HIF1A. Another antisense, HIF1A$A S 2$, is involved in the regulation of HIF-1a [12, 43]. HIF1A-AS2 mRNA was not significantly higher in the $\mathrm{CP}$ of progressive MS patients relative to that of controls, suggesting that HIF1A-AS3 may act as an upstream regulator of the hypoxia responses observed in our study. Altogether, our data indicate that the HIF1 pathway is altered in the $\mathrm{CP}$ of progressive MS patients. We speculate that the transcriptomic profile of the $\mathrm{CP}$ in progressive MS could be influenced by an exposure to hypoxic conditions. A hypoxic environment in progressive MS could originate from a reduction in blood supply at the CP stroma, or as a response to diffusible factors from the CSF compartment. Oxidative stress occurs in MS brains [25, 81], and CSF from MS patients can induce oxidative stress [78]. This suggests that oxidative factors can diffuse from the brain parenchyma into the CSF compartment, reaching the CP epithelium and leading to the respiratory enzyme deficiencies observed in MS patients [9]. Our results point to such an important pathological mechanism occurring at the $\mathrm{CP}$ in progressive MS patients.

One of the functions of the $\mathrm{CP}$ is the maintenance of immune homeostasis in the CNS. Although CNS inflammation is less evident in the progressive phases of MS, immune activation occurs in both the relapsingremitting and progressive MS CP [65, 77]. However, we only detected a subtle alteration in the immunological profile. CXCL2 is a chemokine for granulocytes and, interestingly, neutrophilic LCN2 is upregulated at the onset of EAE [49]. Although no neutrophil markers were differentially expressed in our RNA-seq data, our recent immunohistochemical characterization of immune cell populations in the $\mathrm{CP}$ showed an accumulation of granulocytes in progressive MS patients relative to controls [65]. Future studies should explore the involvement of granulocytes in CP-mediated MS pathology, including whether their release of reactive oxygen species is related to the hypoxia-like responses observed. Previous transcriptomic studies of the $\mathrm{CP}$ from other neurological diseases detected alterations in immune-related pathways [34, 70]. Moreover, our recent study indicated that $\mathrm{CD} 8+\mathrm{T}$ cells are more abundant in progressive MS CP than in control, which we could not detect in the present work. These discrepancies suggest that our bulk RNA-seq approach does not have enough resolution for detecting changes in relatively scarce cell populations, such as are granulocytes and $\mathrm{T}$ cells in the $\mathrm{CP}$. Altogether, our dataset supports the view that strong inflammatory reactions are absent from the progressive MS CP.

Another major role of the $\mathrm{CP}$ is the formation of the $\mathrm{BCSFB}$ at the epithelial tight junctions. In contrast to previous studies [37], we did not identify clear alterations in the barrier properties of the $\mathrm{CP}$ in progressive MS patients. This is in line with other research that showed a lack of involvement of the junctional protein claudin-3 in EAE [13]. Thus, the structural BCSFB properties in progressive MS patients may remain intact and support CNS homeostasis. 
The secretion of CSF is the main function of the CP. The CP has a strategic location to secrete signaling molecules that can reach the CNS periventricular areas, as well as more distant loci such as the cortex or spinal cord. To date, however, secretory alterations of the $\mathrm{CP}$ in neurological diseases have not been sufficiently investigated. Our transcriptome analysis identified three genes coding for secreted proteins with higher expression in the $\mathrm{CP}$ of progressive MS patients. At the protein level, PAI-1 was present in higher concentrations in CSF samples from MS patients with high disability relative to those with low disability. Our findings indicate that $\mathrm{CP}$ epithelial cells may produce ADM and PAI-1, in line with previous studies $[71,72,76,79]$. Data from our lab and a publicly available dataset suggest that the origin of the CSF protein alterations is the $\mathrm{CP}$ and not the brain parenchyma.

PAI-1 (coded by SERPINE1) is a secreted proteinase inhibitor involved in the regulation of fibrinolysis. A genotype associated with low PAI-1 production [53] is a risk factor for MS [47, 84], illustrating its neuroprotective properties. Indeed, PAI-1 has an anti-apoptotic function in neurons [69] and it increases BBB tightness [14]. However, in a chronic relapsing EAE model, SERPINE1 knockout mice showed less disease severity than the wild types [15]. Higher PAI-1 concentrations have been previously detected in the CSF of MS patients compared to that in controls [1]. Moreover, higher SERPINE1 expression was detected in the CP of Alzheimer's and Huntington's disease and frontotemporal dementia patients relative to controls [70]. Our findings suggest that in the most severe cases of progressive MS the CP secretes higher levels of PAI-1 into the CSF, where it can travel into lesion-prone periventricular areas in an attempt to promote neuroprotection. Interestingly, higher levels of PAI-1 have been detected in acute MS lesions compared to control tissue [26]. ADM is a neuroprotective vasodilator $[23,24]$ that can promote oligodendrocyte differentiation [48] and tightening of the BBB [36]. ADM has a therapeutic potential based on its protective effects in EAE [56]. This neuroprotective mechanism does not seem specific for MS, but rather a general response to CNS damage, as ADM concentration is also elevated in the CSF after traumatic brain injury [62] and in ageing cortex [38]. More samples would be needed to determine if ADM is upregulated in the CSF of MS patients.

Previous studies have pointed to the neuroprotective role of the $C P[6,16,17,28]$. In addition to $A D M$ and SERPINE1 (PAI-1), other genes related to neuroprotection presented higher expression in progressive MS $\mathrm{CP}$ relative to control CP. STC2 is a glycoprotein with neuroprotective effects in hippocampal degeneration [8]. Although the concentration of STC2 in the human CSF samples analyzed did not reflect the gene expression, this could be due to a restricted local expression of the peptide. Moreover, two metallothionein genes, MT1A and $M T 1 X$, presented higher expression in progressive MS CP than in control CP. Metallothioneins are antioxidant metal binding molecules recently explored as therapeutic agents [31]. The increased MT1X expression in progressive MS CP may be caused by hypoxia $[68,75]$, or by the higher copper levels present in the CSF of MS patients relative to healthy subjects [50]. Overall, we describe a neuroprotective signature in the $\mathrm{CP}$ of progressive MS patients which may reflect the role of this strategical tissue in restoring brain homeostasis in neurological disease.

Due to its homeostatic secretory activity, the $\mathrm{CP}$ is an interesting candidate as a therapeutic target. An attracting possibility would be to peripherally promote the local production of neuroprotective peptides, such as those identified here, at the $\mathrm{CP}$ and their secretion into the CSF. We observe a dysregulation of the HIF1 pathway in progressive MS CP, accompanied by a higher expression of several neuroprotective genes. Although hypoxic preconditioning can trigger neuroprotective responses [75], a pharmaceutical potentiation of these pathways bypassing the hypoxic exposure would reduce CNS damage. A recent study has described the cannabidiol quinone derivative drug VCE-004.8 as a novel therapeutic tool in MS, partly through the stabilization of HIF- $1 \alpha$ and EPAS1 transcription factors and the activation of the HIF1 pathway [54]. Our findings suggest that the $\mathrm{CP}$ may be a key player in the protective functions of this promising drug, which is currently in phase I clinical trials.

In summary, we here provide comprehensive evidence for the involvement of the CP in progressive MS. Transcriptomic alterations related to hypoxic responses and the secretion of neuroprotective peptides illustrate the ability of the $\mathrm{CP}$ to monitor and respond to changes in the CNS environment. This study highlights the homeostatic capacities and disease alterations of the $\mathrm{CP}$ and suggests that manipulating its secretory properties may influence MS disease pathogenesis and promote neuroprotection.

\section{Supplementary information}

Supplementary information accompanies this paper at https://doi.org/10. 1186/s40478-020-00903-y.

Additional file 1: Supplementary Fig. 1 Transcriptional profile of the human choroid plexus in progressive MS. a Validation by RT-qPCR of genes identified to be differentially expressed by RNA-seq. mRNA expression levels were normalised to the average of two stable reference genes, namely GAPDH and $18 \mathrm{~s}$ rRNA. Each dot corresponds to an individual gene, coloured according to the RT-qPCR p-value. Differences were tested by two-tailed Welch t-test. b Expression in Fragments Per Kilobase Million (FPKM) of the EPAS1-202 isoform in progressive MS and control CP, as assessed by RNA-seq. c Normalised expression of the genes EPAS1 and HIF1A in progressive MS and control CP, as assessed by RNA-seq d PCA 
plot of RNA-seq samples illustrates the high variability in the transcriptional profile. The percentage of data variation explained by the first two principal components (PC1 and PC2) is displayed. Each dot corresponds to an individual sample. PC1 explains most of the sample variation between control and progressive MS cases.

Additional file 2: Supplementary Fig. 2 Hypoxia responses in human CP explants. a HIFIA and HIFIA-AS3 difference in relative gene expression between human postmortem CP paired samples from each donor $(n=6)$ incubated $24 \mathrm{~h}$ in hypoxia $\left(1 \% \mathrm{O}_{2}\right)$ or normoxia $\left(20 \% \mathrm{O}_{2}\right)$ analyzed using qPCR. Data are normalised to $18 \mathrm{~s}$ rRNA. Results are displayed as the negative difference in ct values between hypoxia and normoxia (represented as $-\Delta \Delta \mathrm{ct}$ ) and presented as median with confidence interval. Differences were tested by paired two-tailed Welch t-test.

Additional file 3: Supplementary Fig. 3 Altered concentration of ADM and PAl-1 peptides in the CSF of MS patients. a Correlation plot of ADM protein concentration with age in CSF samples $(n=53)$. Smoothing line is calculated with linear regression, and shadow area represents the confidence interval around the smooth line. b Age of CSF donors with MS ( $n=27)$ or control $(n=26)$, used for ADM protein assessment. Results are displayed as median and interquartile ranges (IQR). Differences were tested by Welch Two Sample t-test. c ADM protein concentration in the CSF of MS patients with high disability (high EDSS; $n=9$ ) or low disability (low EDSS; $n=18$ ), as measured by RIA. Results are displayed as median and interquartile ranges (IQR). Differences were tested by Wilcoxon rank sum test with continuity correction. d Age of CSF donors with high disability (high EDSS; $n=9$ ) or low disability (low EDSS; $n=18$ ), used for ADM protein assessment. Results are displayed as median and interquartile ranges (IQR). Differences were tested by Welch Two Sample t-test. e Correlation plot of PAl-1 protein concentration with age in CSF samples $(n=31)$. Smoothing line is calculated with linear regression, and shadow area represents the confidence interval around the smooth line. $\mathbf{f}$ Age of CSF donors with high disability (high EDSS; $n=9$ ) or low disability (low EDSS; $n=7$ ), used for PAI-1 protein assessment. Results are displayed as median and interquartile ranges (IQR). Differences were tested by Welch Two Sample t-test. $\mathbf{g}$ Correlation plot of STC2 protein concentration with age in CSF samples $(n=37)$. Smoothing line is calculated with linear regression, and shadow area represents the confidence interval around the smooth line. $\mathbf{h}$ STC2 protein concentration in the CSF of MS patients with high disability (high EDSS; $\mathrm{n}=7$ ) or low disability (low EDSS; $\mathrm{n}=8$ ), as measured by ELISA. Results are displayed as median and interquartile ranges (IQR). Differences were tested by Welch Two Sample t-test. i Age of CSF donors with high disability (high EDSS; $\mathrm{n}=7$ ) or low disability (low EDSS; $n=8$ ), used for STC2 protein assessment. Results are displayed as median and interquartile ranges (IQR). Differences were tested by Welch Two Sample t-test.

Additional file 4: Supplementary Fig. 4 Microarray gene expression data extracted from GEO dataset GSE38010. The expression values of the different samples from white matter from healthy controls ('Control) or plaques from MS brains ('Early', 'Active', 'Chronic') are shown a) For ADM, one probe was available (202912 at) b) For SERPINE1 there were two probes available (202627_s_at and 202628_s_at) c) For STC2 there were two probes available (203438_at and 203439_s_at)

Additional file 5: Supplementary Table 1. Details of the human choroid plexus samples used for RNA-seq. F: female, M: male; PMD: Postmortem delay; RIN: RNA integrity number; SP: Secondary Progressive; PP: Primary Progressive. The type of MS is noted in between brackets, as extracted from the clinical report, sometimes unclear

Additional file 6: Supplementary Table 2. Details of the human choroid plexus samples used for explants culture. F: female, M: male; PMD: Post-mortem delay.

Additional file 7: Supplementary Table 3. Details of the human CSF samples used. Patient information is provided, together with an indication of the experiment(s) for which the samples were used. NINDC: non-inflammatory disease controls; SC: symptomatic controls; INDC: inflammatory CNS disease.

Additional file 8: Supplementary Table 4. Details of the human brain samples used. Patient information and lesion type are provided. PMD: Post-mortem delay; CA: chronic active; CIA: chronic inactive.
Additional file 9: Supplementary Table 5. Primer sequences used in qPCR.

Additional file 10: Supplementary Table 6. Gene ontology enrichment analysis. Table displays the GO category ID, the name of the term, the number of differentially expressed (DE) genes in the category and the total number of genes in the category.

Additional file 11: Supplementary Table 7. Results from the gene expression analysis in CP explants in normoxia and hypoxia. Table displays the $p$-values of the difference in expression between the CP explants in normoxia or hypoxia, assessed by paired two-tailed Welch t-test

\section{Acknowledgements}

We would like to thank Dr. P. Koolwijk, Department of Physiology, for his help with the hypoxia station. We are grateful to Dr. Reinier Boon for his advice on HIFIA-AS3, and to Ricardo Figueiredo for inspiring discussions. We want to thank Dr. J. van Horssen for the CSF samples.

\section{Authors' contributions}

SRL, with the help of DF, GK and HdV conceived the study. SRL and DF analyzed the RNA-sequencing data, and DF performed the isoform analysis, with the supervision of RB. SRL performed most of the experiments and BvhH helped with gene expression experiments. RV, WB and SRL designed and performed the RIA assay. MR isolated brain lesion material. HS and HI provided the HIBCPP cell line and helped establishing cell culture. GK and HdV provided supervision. SRL wrote the manuscript with the help of DF, MR, GK and HdV. All the authors have read and approved the manuscript.

\section{Funding}

This project has been funded by the EU Horizon 2020 MSCA-ITN-2015 675619 BtRAIN and a Dutch MS Research Foundation grant (14-878MS to GK). SRL received a NAUTA MS travel grant.

\section{Availability of data and materials}

The RNA-seq dataset is available in the GEO database under the accession number GSE137619.

\section{Ethics approval and consent to participate}

CP tissue from the lateral ventricles was obtained from the Netherlands Brain Bank, while brain tissue was obtained from the UK MS Society Tissue Bank, Imperial College London. All parties received permission to perform autopsies, for the use of tissue and for access to medical records for research purposes. All donors or their next of kin, had given informed consent for autopsy and use of their brain tissue for research purposes.

\section{Consent for publication}

Not applicable.

\section{Competing interests}

The authors declare that they have no competing interests.

\section{Author details}

'Department of Molecular Cell Biology and Immunology, Amsterdam Neuroscience, MS Center Amsterdam, Amsterdam UMC, Vrije Universiteit Amsterdam, de Boelelaan 1117, 1007 MB Amsterdam, Netherlands. ${ }^{2}$ Interfaculty Bioinformatics Unit and Swiss Institute of Bioinformatics, University of Bern, Bern, Switzerland. ${ }^{3}$ Department of Radiology \& Nuclear Medicine, Amsterdam UMC, Amsterdam, the Netherlands. ${ }^{4}$ Pediatric Infectious Diseases, University Children's Hospital Manheim, Medical Faculty Manheim, Heidelberg University, Manheim, Germany. ${ }^{5}$ Laboratory of Clinical Regenerative Medicine, Department of Neurosurgery, Faculty of Medicine, University of Tsukuba, Tsukuba, Japan. ${ }^{6}$ Medical Biochemistry, Amsterdam Cardiovascular Sciences, Amsterdam UMC, University of Amsterdam, Meibergdreef 9, Amsterdam $1105 \mathrm{AZ}$, the Netherlands. 
Received: 7 January 2020 Accepted: 29 February 2020 Published online: 19 March 2020

\section{References}

1. Akenami F, Koskiniemi M, Färkkilä M, Vaheri A (1997) Cerebrospinal fluid plasminogen activator inhibitor-1 in patients with neurological disease. Clin Pathol 50:157-160

2. Barrett T, Wilhite SE, Ledoux P, Evangelista C, Kim IF, Tomashevsky M, Marshal KA, Phillippy KH, Sherman PM, Holko M (2012) NCBI GEO: archive for functional genomics data sets - update. Nucleic Acids Res 41:D991-D995

3. Baruch K, Schwartz M (2013) CNS-specific T cells shape brain function via the choroid plexus. Brain Behav Immun 34:11-16

4. Bioinformatics B (2011) FastQC: a quality control tool for high throughput sequence data. Babraham Institute, Cambridge, UK

5. Bo C, Xingyu M, Wei S, Jingnan $P$, Chongxiao L, Zhenyu G, Fangru W (2013) The expressions of brain-derived neurotrophic factor and nerve growth factor in purified rat choroid plexus epithelial cells in vitro. J Med Coll PLA 28:257-267

6. Borlongan CV, Skinner SJ, Geaney M, Vasconcellos AV, Elliott RB, Emerich DF (2004) Intracerebral transplantation of porcine choroid plexus provides structural and functional neuroprotection in a rodent model of stroke. Stroke 35:2206-2210

7. Browne P, Chandraratna D, Angood C, Tremlett H, Baker C, Taylor BV, Thompson A (2014) Atlas of multiple sclerosis 2013: a growing global problem with widespread inequity. Neurology 83:1022-1024. https:/doi.org/10.1212/wnl.0000000000000768

8. Byun J-S, Lee J-W, Kim SY, Kwon KJ, Sohn J-H, Lee K, Oh D, Kim S-S, Chun W, Lee HJ (2010) Neuroprotective effects of stanniocalcin 2 following kainic acidinduced hippocampal degeneration in ICR mice. Peptides 31:2094-2099

9. Campbell GR, Kraytsberg Y, Krishnan KJ, Ohno N, Ziabreva I, Reeve A, Trapp BD, Newcombe J, Reynolds R, Lassmann H (2012) Clonally expanded mitochondrial DNA deletions within the choroid plexus in multiple sclerosis. Acta Neuropathol 124:209-220

10. Cejudo-Martín P, Morales-Ruiz M, Ros J, Navasa M, Fernández-Varo G, Fuster J, Rivera F, Arroyo V, Rodés J, Jiménez W (2002) Hypoxia is an inducer of vasodilator agents in peritoneal macrophages of cirrhotic patients. Hepatology 36:1172-1179

11. Cepok S, Jacobsen M, Schock S, Omer B, Jaekel S, Boddeker I, Oertel WH, Sommer N, Hemmer B (2001) Patterns of cerebrospinal fluid pathology correlate with disease progression in multiple sclerosis. Brain 124:2169-2176. https://doi.org/10.1093/brain/124.11.2169

12. Chen D, Wu L, Liu L, Gong Q, Zheng J, Peng C, Deng J (2017) Comparison of HIF1A-AS1 and HIF1A-AS2 in regulating HIF-1a and the osteogenic differentiation of PDLCs under hypoxia. Int J Mol Med 40:1529-1536

13. Dias MC, Coisne C, Lazarevic I, Baden P, Hata M, Iwamoto N, Francisco DMF, Vanlandewijck M, He L, Baier FA (2019) Claudin-3-deficient C57BL/6J mice display intact brain barriers. Sci Rep 9:1-16

14. Dohgu S, Takata F, Matsumoto J, Oda M, Harada E, Watanabe T, Nishioku T, Shuto H, Yamauchi A, Kataoka Y (2011) Autocrine and paracrine upregulation of blood-brain barrier function by plasminogen activator inhibitor-1. Microvasc Res 81:103-107

15. East E, Gverić D, Baker D, Pryce G, Lijnen H, Cuzner M (2008) Chronic relapsing experimental allergic encephalomyelitis (CREAE) in plasminogen activator inhibitor-1 knockout mice: the effect of fibrinolysis during neuroinflammation. Neuropathol Appl Neurobiol 34:216-230

16. Emerich DF, Schneider P, Bintz B, Hudak J, Thanos CG (2007) Aging reduces the neuroprotective capacity, VEGF secretion, and metabolic activity of rat choroid plexus epithelial cells. Cell Transplant 16:697-705

17. Emerich DF, Thanos CG, Goddard M, Skinner SJ, Geany MS, Bell WJ, Bintz B, Schneider P, Chu Y, Babu RS (2006) Extensive neuroprotection by choroid plexus transplants in excitotoxin lesioned monkeys. Neurobiol Dis 23:471-480

18. Fang $\mathrm{H}-\mathrm{Y}$, Hughes $\mathrm{R}$, Murdoch $\mathrm{C}$, Coffelt SB, Biswas SK, Harris AL, Johnson RS, Imityaz HZ, Simon MC, Fredlund E (2009) Hypoxia-inducible factors 1 and 2 are important transcriptional effectors in primary macrophages experiencing hypoxia. Blood, The Journal of the American Society of Hematology 114:844-859

19. Fu J, Frazee AC, Collado-Torres L, Jaffe AE, Leek JT (2018) Ballgown: flexible, isoform-level differential expression analysis. $R$ package version 2

20. Garayoa M, Martínez A, Lee S, Pío R, An WG, Neckers L, Trepel J, Montuenga LM, Ryan H, Johnson R (2000) Hypoxia-inducible factor-1 (HIF-1) upregulates adrenomedullin expression in human tumor cell lines during oxygen deprivation: a possible promotion mechanism of carcinogenesis. Mol Endocrinol 14:848-862
21. García-Alcalde F, Okonechnikov K, Carbonell J, Cruz LM, Götz S, Tarazona S, Dopazo J, Meyer TF, Conesa A (2012) Qualimap: evaluating next-generation sequencing alignment data. Bioinformatics 28:2678-2679

22. Ghersi-Egea J-F, Strazielle N, Catala M, Silva-Vargas V, Doetsch F, Engelhardt B (2018) Molecular anatomy and functions of the choroidal blood-cerebrospinal fluid barrier in health and disease. Acta Neuropathol 135:337-361

23. Gonzalez-Rey E, Chorny A, Delgado M (2007) Regulation of immune tolerance by anti-inflammatory neuropeptides. Nat Rev Immunol 7:52-63

24. Gonzalez-Rey E, Delgado-Maroto V, Souza-Moreira L, Delgado M (2010) Neuropeptides as therapeutic approach to autoimmune diseases. Curr Pharm Des 16:3158-3172

25. Graumann U, Reynolds R, Steck AJ, Schaeren-Wiemers N (2003) Molecular changes in normal appearing white matter in multiple sclerosis are characteristic of neuroprotective mechanisms against hypoxic insult. Brain Pathol 13:554-573

26. Gverić D, Herrera B, Petzold A, Lawrence DA, Cuzner ML (2003) Impaired fibrinolysis in multiple sclerosis: a role for tissue plasminogen activator inhibitors. Brain 126:1590-1598

27. Han MH, Lundgren DH, Jaiswal S, Chao M, Graham KL, Garris CS, Axtell RC, Ho PP, Lock CB, Woodard II (2012) Janus-like opposing roles of CD47 in autoimmune brain inflammation in humans and mice. J Exp Med 209:1325-1334

28. Ide C, Kitada M, Chakrabortty S, Taketomi M, Matsumoto N, Kikukawa S, Mizoguchi A, Kawaguchi S, Endoh K, Suzuki Y (2001) Grafting of choroid plexus ependymal cells promotes the growth of regenerating axons in the dorsal funiculus of rat spinal cord: a preliminary report. Exp Neurol 167:242-251

29. Ishiwata I, ISHIWAT C, Ishiwata E, Sato Y, Kiguchi K, Tachibana T, Hashimoto $\mathrm{H}$, Ishikawa $\mathrm{H}$ (2005) Establishment and characterization of a human malignant choroids plexus papilloma cell line (HIBCPP). Hum Cell 18:67-72

30. Johanson C, McMillan P, Tavares R, Spangenberger A, Duncan J, Silverberg G, Stopa E (2004) Homeostatic capabilities of the choroid plexus epithelium in Alzheimer's disease. Cerebrospinal Fluid Res 1:3

31. Kang YC, Son M, Kang S, Im S, Piao Y, Lim KS, Song M-Y, Park K-S, Kim Y-H, Pak YK (2018) Cell-penetrating artificial mitochondria-targeting peptideconjugated metallothionein $1 \mathrm{~A}$ alleviates mitochondrial damage in Parkinson's disease models. Exp Mol Med 50:1-13

32. Kim D, Langmead B, Salzberg SL (2015) HISAT: a fast spliced aligner with low memory requirements. Nat Methods 12:357-360

33. Kim D, Pertea G, Trapnell C, Pimentel H, Kelley R, Salzberg SL (2013) TopHat2: accurate alignment of transcriptomes in the presence of insertions, deletions and gene fusions. Genome Biol 14:R36

34. Kim S, Hwang Y, Lee D, Webster MJ (2016) Transcriptome sequencing of the choroid plexus in schizophrenia. Transl Psychiatry 6:e964-e964

35. Kimura D, Imaizumi T, Tamo W, SAKAI T, Ito K, HATANAKA R, Yoshida H, Tsushima T, Satoh K, Fukuda I (2002) Hypoxia enhances the expression of plasminogen activator inhibitor-1 in human lung cancer cells, EBC-1. Tohoku J Exp Med 196:259-267

36. Kis B, Deli MA, Kobayashi H, Ábrahám CS, Yanagita T, Kaiya H, Isse T, Nishi R, Gotoh S, Kangawa K (2001) Adrenomedullin regulates blood-brain barrier functions in vitro. Neuroreport 12:4139-4142

37. Kooij G, Kopplin K, Blasig R, Stuiver M, Koning N, Goverse G, van der Pol SM, van het Hof B, Gollasch M, Drexhage JA (2014) Disturbed function of the blood-cerebrospinal fluid barrier aggravates neuro-inflammation. Acta Neuropathol 128:267-277

38. Larrayoz IM, Ferrero H, Martisova E, Gil-Bea FJ, Ramírez MJ, Martínez A (2017) Adrenomedullin contributes to age-related memory loss in mice and is elevated in aging human brains. Front Mol Neurosci 10:384

39. Lassmann H, van Horssen J, Mahad D (2012) Progressive multiple sclerosis: pathology and pathogenesis. Nat Rev Neurol 8:647-656. https:/doi.org/10.1038/nrneurol.2012.168

40. Law AY, Wong CK (2010) Stanniocalcin-2 is a HIF-1 target gene that promotes cell proliferation in hypoxia. Exp Cell Res 316:466-476

41. Leek J (2019) Sva: surrogate variable analysis. R package version 3.26. 0. Bioconductor

42. Li H (2011) A statistical framework for SNP calling, mutation discovery, association mapping and population genetical parameter estimation from sequencing data. Bioinformatics 27:2987-2993

43. Li L, Wang M, Mei Z, Cao W, Yang Y, Wang Y, Wen A (2017) IncRNAs HIF1AAS2 facilitates the up-regulation of HIF-1a by sponging to miR-153-3p, whereby promoting angiogenesis in HUVECs in hypoxia. Biomed Pharmacother 96:165-172

44. Liao H, Hyman MC, Lawrence DA, Pinsky DJ (2007) Molecular regulation of the PAl-1 gene by hypoxia: contributions of Egr-1, HIF-1a, and C/EBPa. FASEB J 21:935-949 
45. Love MI, Huber W, Anders S (2014) Moderated estimation of fold change and dispersion for RNA-seq data with DESeq2. Genome Biol 15:550

46. Lublin FD, Reingold SC (1996) Defining the clinical course of multiple sclerosis: results of an international survey. National Multiple Sclerosis Society (USA) Advisory Committee on Clinical Trials of New Agents in Multiple Sclerosis Neurology 46:907-911. https://doi.org/10.1212/wnl.46.4.907

47. Luomala M, Elovaara I, Ukkonen M, Koivula T, Lehtimäki T (2000) Plasminogen activator inhibitor 1 gene and risk of MS in women. Neurology 54:1862-1864

48. Maki T, Takahashi Y, Miyamoto N, Liang AC, Ihara M, Lo EH, Arai K (2015) Adrenomedullin promotes differentiation of oligodendrocyte precursor cells into myelin-basic-protein expressing oligodendrocytes under pathological conditions in vitro. Stem Cell Res 15:68-74

49. Marques F, Mesquita SD, Sousa JC, Coppola G, Gao F, Geschwind DH, ColumbaCabezas S, Aloisi F, Degna M, Cerqueira JJ (2012) Lipocalin 2 is present in the EAE brain and is modulated by natalizumab. Front Cell Neurosci 6:33

50. Melø TM, Larsen C, White LR, Aasly J, Sjøbakk TE, Flaten TP, Sonnewald U, Syversen T (2003) Manganese, copper, and zinc in cerebrospinal fluid from patients with multiple sclerosis. Biol Trace Elem Res 93:1-8

51. Meyer-Moock S, Feng Y-S, Maeurer M, Dippel F-W, Kohlmann T (2014) Systematic literature review and validity evaluation of the expanded disability status scale (EDSS) and the multiple sclerosis functional composite (MSFC) in patients with multiple sclerosis. BMC Neurol 14:58

52. Mineo M, Ricklefs F, Rooj AK, Lyons SM, Ivanov P, Ansari KI, Nakano I, Chiocca EA, Godlewski J, Bronisz A (2016) The long non-coding RNA HIF1AAS2 facilitates the maintenance of mesenchymal glioblastoma stem-like cells in hypoxic niches. Cell Rep 15:2500-2509

53. Muñoz-Valle JF, Ruiz-Quezada SL, Oregón-Romero E, Navarro-Hernández RE, Castañeda-Saucedo E, De la Cruz-Mosso U, Illades-Aguiar B, Leyva-Vázquez MA, Castro-Alarcón N, Parra-Rojas I (2012) PAl-1 mRNA expression and plasma level in rheumatoid arthritis: relationship with 4G/5G PAI-1 polymorphism. Rheumatol Int 32:3951-3956

54. Navarrete C, Carrillo-Salinas F, Palomares B, Mecha M, Jiménez-Jiménez C, Mestre L, Feliú A, Bellido ML, Fiebich BL, Appendino G (2018) Hypoxia mimetic activity of VCE-004.8, a cannabidiol quinone derivative: implications for multiple sclerosis therapy. J Neuroinflammation 15:64

55. Nguyen SV, Claycomb WC (1999) Hypoxia regulates the expression of the adrenomedullin and HIF-1 genes in cultured $\mathrm{HL}-1$ cardiomyocytes. Biochem Biophys Res Commun 265:382-386

56. Pedreño M, Morell M, Robledo G, Souza-Moreira L, Forte-Lago I, Caro M, O'Valle F, Ganea D, Gonzalez-Rey E (2014) Adrenomedullin protects from experimental autoimmune encephalomyelitis at multiple levels. Brain Behav Immun 37:152-163

57. Pertea M, Pertea GM, Antonescu CM, Chang T-C, Mendell JT, Salzberg SL (2015) StringTie enables improved reconstruction of a transcriptome from RNA-seq reads. Nat Biotechnol 33:290

58. Reboldi A, Coisne C, Baumjohann D, Benvenuto F, Bottinelli D, Lira S, Uccelli A, Lanzavecchia A, Engelhardt B, Sallusto F (2009) C-C chemokine receptor 6-regulated entry of $\mathrm{TH}-17$ cells into the CNS through the choroid plexus is required for the initiation of EAE. Nat Immunol 10:514-523. https://doi.org/10.1038/ni.1716

59. Reich DS, Lucchinetti CF, Calabresi PA (2018) Multiple Sclerosis. N Engl J Med 378:169-180. https://doi.org/10.1056/NEJMra1401483

60. Riddle SR, Ahmad A, Ahmad S, Deeb SS, Malkki M, Schneider BK, Allen CB, White CW (2000) Hypoxia induces hexokinase II gene expression in human lung cell line A549. Am J Phys Lung Cell Mol Phys 278:L407-L416

61. Ritchie ME, Phipson B, Wu D, Hu Y, Law CW, Shi W, Smyth GK (2015) Limma powers differential expression analyses for RNA-sequencing and microarray studies. Nucleic Acids Res 43:e47-e47

62. Robertson CL, Minamino N, Ruppel RA, Kangawa K, Wisniewski SR, Tsuji T, Janesko KL, Ohta H, Adelson PD, Marion DW (2001) Increased adrenomedullin in cerebrospinal fluid after traumatic brain injury in infants and children. J Neurotrauma 18:861-868

63. Robinson JT, Thorvaldsdóttir H, Winckler W, Guttman M, Lander ES, Getz G, Mesirov JP (2011) Integrative genomics viewer. Nat Biotechnol 29:24-26

64. Robinson MD, McCarthy DJ, Smyth GK (2010) edgeR: a bioconductor package for differential expression analysis of digital gene expression data. Bioinformatics 26:139-140

65. Rodriguez-Lorenzo S, Konings J, van der Pol S, Kamermans A, Amor S, van Horssen J, Witte M, Kooij G, de Vries HE (2020) Inflammation of the choroid plexus in progressive multiple sclerosis: accumulation of granulocytes and $\mathrm{T}$ cells. Acta neuropathologica communications 8:9. https://doi.org/10.1186/ s40478-020-0885-1
66. Rothstein RP, Levison SW (2002) Damage to the choroid plexus, ependyma and subependyma as a consequence of perinatal hypoxia/ischemia. Dev Neurosci 24:426-436

67. Sato M, Tanaka T, Maemura K, Uchiyama T, Sato H, Maeno T, Suga T, Iso T, Ohyama Y, Arai M (2004) The PAl-1 gene as a direct target of endothelial PAS domain protein-1 in adenocarcinoma A549 cells. Am J Respir Cell Mol Biol 31:209-215

68. Schulkens IA, Castricum KC, Weijers EM, Koolwijk P, Griffioen AW, Thijssen VL (2014) Expression, regulation and function of human metallothioneins in endothelial cells. J Vasc Res 51:231-238

69. Soeda S, Koyanagi S, Kuramoto Y, Kimura M, Oda M, Kozako T, Hayashida S, Shimeno H (2008) Anti-apoptotic roles of plasminogen activator inhibitor-1 as a neurotrophic factor in the central nervous system. Thromb Haemost 100:1014-1020

70. Stopa EG, Tanis KQ, Miller MC, Nikonova EV, Podtelezhnikov AA, Finney EM, Stone DJ, Camargo LM, Parker L, Verma A (2018) Comparative transcriptomics of choroid plexus in Alzheimer's disease, frontotemporal dementia and Huntington's disease: implications for CSF homeostasis. Fluids and Barriers of the CNS 15:18

71. Takahashi K, Satoh F, Hara E, Murakami O, Kumabe T, Tominaga T, Kayama T, Yoshimoto T, Shibahara S (1997) Production and secretion of adrenomedullin by cultured choroid plexus carcinoma cells. J Neurochem 68:726-731

72. Takano M, Uramoto M, Otani M, Matsuura K, Sano K, Matsuyama S (2014) Secretomic analysis of mouse choroid plexus cell line ECPC-4 using twodimensional gel electrophoresis coupled to mass spectrometry. Journal of Proteomics \& Bioinformatics 7:347

73. Tani H, Okuda S, Nakamura K, Aoki M, Umemura T (2017) Short-lived long non-coding RNAs as surrogate indicators for chemical exposure and LINC00152 and MALAT1 modulate their neighboring genes. PloS one 12

74. Team RC (2013) R: a language and environment for statistical computing

75. Thiersch M, Raffelsberger W, Frigg R, Samardzija M, Wenzel A, Poch O, Grimm C (2008) Analysis of the retinal gene expression profile after hypoxic preconditioning identifies candidate genes for neuroprotection. BMC Genomics 9:73

76. Thouvenot E, Lafon-Cazal M, Demettre E, Jouin P, Bockaert J, Marin P (2006) The proteomic analysis of mouse choroid plexus secretome reveals a high protein secretion capacity of choroidal epithelial cells. Proteomics 6:5941-5952

77. Vercellino M, Votta B, Condello C, Piacentino C, Romagnolo A, Merola A, Capello E, Mancardi GL, Mutani R, Giordana MT, Cavalla P (2008) Involvement of the choroid plexus in multiple sclerosis autoimmune inflammation: a neuropathological study. J Neuroimmunol 199:133-141. https://doi.org/10.1016/j.jneuroim.2008.04.035

78. Vidaurre OG, Haines JD, Katz Sand I, Adula KP, Huynh JL, McGraw CA, Zhang F, Varghese M, Sotirchos E, Bhargava P (2014) Cerebrospinal fluid ceramides from patients with multiple sclerosis impair neuronal bioenergetics. Brain 137:2271-2286

79. Washimine H, Asada Y, Kitamura K, Ichiki Y, Hara S, Yamamoto Y, Kangawa K, Sumiyoshi A, Eto T (1995) Immunohistochemical identification of adrenomedullin in human, rat, and porcine tissue. Histochem Cell Biol 103:251-254

80. Wiesener M, Turley H, Allen W, Willam C, Eckardt K-U, Talks K, Wood S, Gatter K, Harris A, Pugh C (1998) Induction of endothelial PAS domain protein-1 by hypoxia: characterization and comparison with hypoxiainducible factor-1a. Blood, The Journal of the American Society of Hematology 92:2260-2268

81. Zeis T, Graumann U, Reynolds R, Schaeren-Wiemers N (2008) Normalappearing white matter in multiple sclerosis is in a subtle balance between inflammation and neuroprotection. Brain 131:288-303

82. Zhang Y, Sloan SA, Clarke LE, Caneda C, Plaza CA, Blumenthal PD, Vogel H, Steinberg GK, Edwards MS, Li G (2016) Purification and characterization of progenitor and mature human astrocytes reveals transcriptional and functional differences with mouse. Neuron 89:37-53

83. Zhu L, Stein LR, Kim D, Ho K, Yu G-Q, Zhan L, Larsson TE, Mucke L (2018) Klotho controls the brain-immune system interface in the choroid plexus. Proc Natl Acad Sci 115:E11388-E11396

84. Živković M, Starčević Čizmarević N, Lovrečić L, Klupka-Sarić I, Stanković A, Gašparović I, Lavtar P, Dinčić E, Stojković L, Rudolf G (2014) The role of TPA I/D and PAI-1 4G/5G polymorphisms in multiple sclerosis. Dis Markers 2014

\section{Publisher's Note}

Springer Nature remains neutral with regard to jurisdictional claims in published maps and institutional affiliations. 